\title{
Correlation Between the Total Small Bowel Length and Anthropometric Measures in Living Humans: Cross-Sectional Study
}

\author{
Mohamed Bekheit ${ }^{1,2,3} \mathbb{D} \cdot$ Mohamed Y. Ibrahim $^{4} \cdot$ Wael Tobar $^{4} \cdot$ Ibrahim Galal ${ }^{4} \cdot$ Athar S. Elward $^{4}$
}

Published online: 5 November 2019

(C) The Author(s) 2019

\begin{abstract}
Background Variation in the outcome of bariatric surgery is still an unraveled phenomenon. This variation could be multifactorial. Several reports implicate the total small bowel length (TSBL) in this process. However, the basic information regarding the normal bowel length and its relation to the anthropometric parameters of the living subject is scarce. This study aims at reporting the normal total bowel length in living adult humans and its correlation with the anthropometric parameters.

Methods This study included 606 participants ( 380 females and 226 males). Their mean age was $39.8 \pm 11$ years, weight $=135.7$ $\pm 29.7 \mathrm{~kg}$, height $=165 \pm 9 \mathrm{~cm}$, and BMI $=49.5 \pm 7.5 \mathrm{~kg} / \mathrm{m}^{2}$.

The mean TSBL was $630 \pm 175 \mathrm{~cm}$. There was a statistically significant but very weak positive correlation but between the TSBL and both weight and height.

Males had significantly higher weight and were significantly taller compared with females. TSBL was significantly longer in males at $661.5 \pm 186 \mathrm{~cm}$ versus $612 \pm 164 \mathrm{~cm}$ in females.

Conclusion The study reports an average TSBL greater than what is reported in the literature from living humans with a greater range of variation. There is no clinically important correlation between the TSBL and the weight and height of the individual participants in this series.
\end{abstract}

Keywords Small bowel $\cdot$ Total bowel length $\cdot$ BMI $\cdot$ Height $\cdot$ Weight

Mohamed Bekheit

dr_mohamedbekheit@hotmail.com

Mohamed Y. Ibrahim

dr.mohamed_yehia@yahoo.com

Wael Tobar

waeltobar@yahoo.com

Ibrahim Galal

ibrahimghk@yahoo.com

Athar S. Elward

athar.elward@kasralainy.edu.eg

1 Department of Surgery, Aberdeen Royal Infirmary, Foresterhill Health Campus, Aberdeen AB25 2ZN, UK

2 Institute of Medical Sciences, University of Aberdeen, Aberdeen, UK

3 Department of Surgery, El-Kabbary Hospital, Alexandria, Egypt

4 Department of General Surgery, Faculty of Medicine, Cairo University, Cairo, Egypt

\section{Background}

Morbid obesity is a global challenge that has attracted the attention of the healthcare providers over the decades [1]. Many options are currently available for the treatment of morbid obesity $[2,3]$. The surgical treatment represents the most effective and probably the most durable solution [4]. The surgical armamentarium is equipped with several techniques [5]. Restrictive procedures are less successful on the long term compared with diversional procedures [6].

Weight regain and inadequate weight loss are among the major challenges after most of the bariatric surgeries. Furthermore, weight loss after the same procedure varies considerably among patients [7]. One of the possible explanatory factors to this phenomenon could be the variation in the length of the bypassed and/or the common bowel segments.

The precise importance of the impact of the total small bowel length (TSBL) on bariatric surgery remains elusive [8]. However, the TSBL could be an influential factor on the weight loss after bariatric surgery [9]. It was reported that 
Table 1 Descriptive statistics of the quantitative baseline variables assessed for this study

\begin{tabular}{lrrrrr}
\hline & Age (years) & Weight $(\mathrm{kg})$ & Height $(\mathrm{cm})$ & BMI $\left(\mathrm{kg} / \mathrm{m}^{2}\right)$ & TSBL $(\mathrm{cm})$ \\
\hline Mean & 39.82 & 135.69 & 165.32 & 49.53 & 630.68 \\
Std. deviation & 11.04 & 29.74 & 9.11 & 9.47 & 174.74 \\
Minimum & 15.00 & 64.00 & 140.00 & 24.69 & 250.00 \\
Maximum & 66.00 & 240.00 & 196.00 & 81.80 & 1300.00 \\
\hline
\end{tabular}

different lengths of bypassed segments might influence the weight loss after RYGBP [10].

The reported TSBL in the literature was predominantly measured in deceased persons or during necropsies [11-13]. In vivo measurements were shown to be different from the measures obtained from cadaveric studies [14]. Prediction of the TSBL could be useful to avoid intraoperative measurements, which might consume extra time particularly in laparoscopic procedures in morbidly obese individuals. A CT scan-based prediction method has been proposed in the literature but without validation [15]. There is significant controversy on the role of anthropometry as predictive parameters to the TSBL $[8,16]$. Therefore, the present study aims at measuring the TSBL in relation to the weight, height, and BMI of living adults.

\section{Aim of the Study}

The aim of this study is to establish the relation between the TSBL and anthropometric parameters.

\section{Study Methods}

The study protocol was approved by the institutional ethics committee of the participant universities in accordance with the 1964 Helsinki declaration and its later amendments.
An informed consent was obtained from all individual participants included in the study. Adults ( $\geq 18$ years) who were submitted to abdominal surgery were considered eligible for inclusion in this study. There was an exception for this role where 3 cases were included between 15 and 18 years based on the judgment of competency and in accordance with the Egyptian Law No. 1 of 2000 (Regulating Litigation Procedures in Personal Status Affairs), Art. 2. Both genders submitted to abdominal surgery and who met the inclusion criteria were approached for consenting for inclusion in the study. Subjects with history of malignancy, previous small bowel resection, or those who were not able to provide consent were excluded from the study.

The study included 606 consecutive participants who met the inclusion criteria and had abdominal surgery between 1 January 2016 and 30 December 2018. The study took place in multiple hospitals in Al Kasr El-Eini University of Cairo main Hospital and the Alexandria main University Hospital. In addition, the study included cases from El-Kabbary Hospital and three other private hospitals in Alexandria.

The measurement of the intestine was obtained starting at the ligament of Treitz and ending at the ileocecal junction. Small bowel length will be expressed in centimeters. All measurements were obtained by two trained surgeons. The measurements were performed using sterile tapes of $10 \mathrm{~cm}$ applied to the antimesenteric border in the natural position with no or minimal stretching.
Fig. 1 Correlation scatter plot of the TSBL and a weight, $\mathbf{b}$ height, c BMI, and $\mathbf{d}$ age for all patients
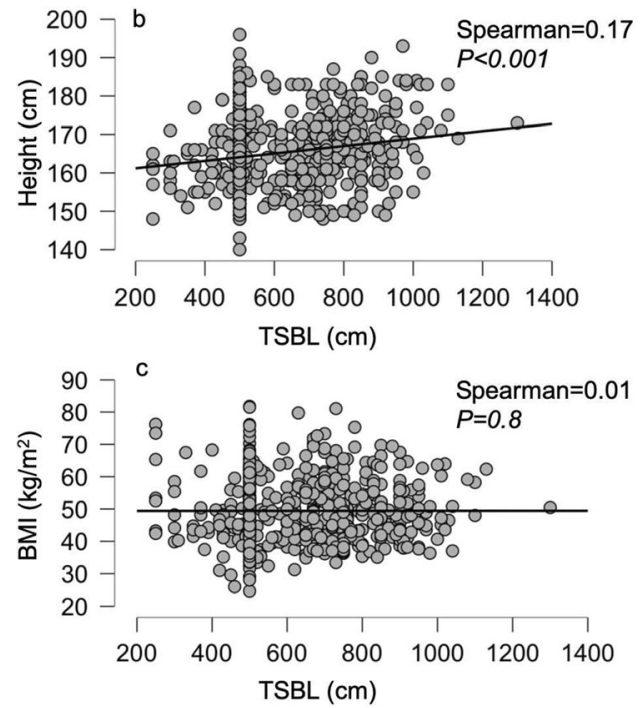

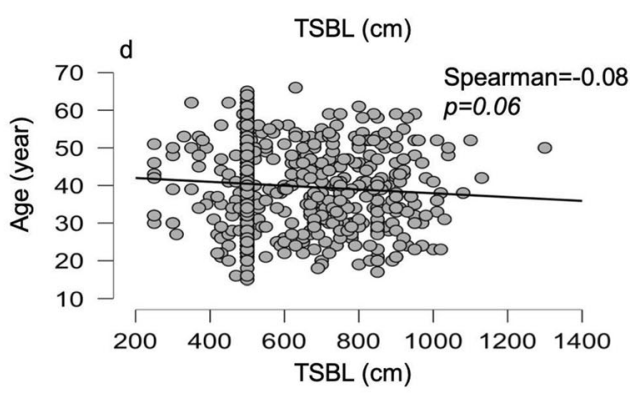


Table 2 Pearson correlation between TSBL and the measured variables in the study

\begin{tabular}{llllll}
\hline & & Age & Weight & Height & BMI \\
\hline TSBL & Pearson's $r$ & -0.08 & 0.09 & 0.19 & 0.00 \\
& $p$ value & 0.05 & 0.03 & $<0.001$ & 0.98 \\
Upper 95\% CI & -0.00 & 0.17 & 0.26 & 0.08 \\
Lower 95\% CI & -0.16 & 0.01 & 0.11 & -0.08 \\
Spearman's rho & -0.08 & 0.10 & 0.17 & 0.01 \\
& $p$ value & 0.06 & 0.01 & $<0.001$ & 0.80 \\
Upper 95\% CI & 0.00 & 0.18 & 0.25 & 0.09 \\
Lower 95\% CI & -0.16 & 0.02 & 0.10 & -0.07 \\
\hline
\end{tabular}

Patients' heights, weight, age, and gender information were recorded on the day of surgery. Patients' BMI was calculated based on the formula BMI = weight in kilograms/(height in meters $)^{2}$. Quantitative variables were summarized in means and standard deviation or $95 \%$ confidence interval. Nominal data were presented in frequency. Percentages were supplied out of the total for categorical variables.

After normality check, the difference in the means of quantitative continuous variables was calculated using Student's $t$ test. Chi-square tests were used to assess the differences in the distribution of categorical variables.

Boxplot was provided to visually demonstrate the difference between quantitative variables and scatter plot to demonstrate the correlation between them. Data were analyzed in JASP software, JASP Team (2018). JASP (Version 0.10.0) (Computer software).

\section{Results}

The study included 380 females and 226 males representing $63 \%$ and $37 \%$, respectively, of the study population. The mean age was $39.8 \pm 11$ years, weight $=135.7 \pm 29.7 \mathrm{~kg}$, height $=165 \pm 9 \mathrm{~cm}$, and BMI $=49.5 \pm 7.5 \mathrm{~kg} / \mathrm{m}^{2}$.

The measurement of the TSBL in the study participants yielded a mean of $630 \pm 175 \mathrm{~cm}$ ranging from 250 to 1300 $\mathrm{cm}$. Table 1 summarizes the TSBL and other anthropometric measures.
The relationship between the TSBL and the other anthropometric parameters was assessed using a simple correlation matrix. There was very weak (i.e., negligible) positive but statistically significant correlation between the TSBL and both weight and height. There was no significant correlation between the TSBL and BMI or the age on the other hand (Fig. 1, Table 2).

On the assessment of the gender influence on the various anthropometric measures and the TSBL, males had significantly higher weight and were significantly taller compared with females (Table 3). There was no difference in the BMI or age between males and females. However, the TSBL was significantly longer in males compared with females. The mean TSBL in males was $661.5 \pm 186 \mathrm{~cm}$ versus $612 \pm$ $164 \mathrm{~cm}$ (Fig. 2). Correlation plots between the different variables in females and males are depicted in Figs. 3 and 4.

\section{Discussion}

This study is the largest reported in the literature. The mean measured TSBL is $6.3 \mathrm{~m}$ with a range that varies from 2.5 to $13 \mathrm{~m}$. In vivo studies on the small bowel length are surprisingly scarce. Teitelbaum et al. reported in an operative series of 240 patients a mean length of the small bowel of approximately $5 \mathrm{~m}$, which is shorter by a meter than our report. Backman reported $6.6 \mathrm{~m}$ average of the small bowel in his operative series [17].

Hounnou studied the TSBL in 200 cadavers and measured a slightly shorter TSBL than the reported one in this study [18]. Several post-mortem studies have reported similar findings to ours $[11,19]$.

While most of the studies have reported an average around $6 \mathrm{~m}$, the variation that we reported in the measured length is larger than previous reports. The shortest TSBL measured in this series is $2.5 \mathrm{~m}$, which is slightly shorter than the shortest reported [14]. While the longest TSBL was in our study $13 \mathrm{~m}$, the longest reported in the literature was approximately $10 \mathrm{~m}$ [20]. One of the potential reasons for this observation is the larger sample size in this study. In addition, the longest measures are anticipated rare in our population given that the data appeared positively skewed. We suspect that these high values were detected as a result of the large sample size and they are not a common finding in the population.

Table 3 Descriptive statistics of the included variables according to gender

\begin{tabular}{|c|c|c|c|c|c|c|c|c|c|c|}
\hline & Age (years) & & Weight $(\mathrm{kg})$ & & Height $(\mathrm{cm})$ & & BMI $\left(\mathrm{kg} / \mathrm{m}^{2}\right)$ & & TSBL $(\mathrm{cm})$ & \\
\hline & $\mathrm{F}$ & M & $\mathrm{F}$ & M & $\mathrm{F}$ & M & $\mathrm{F}$ & M & $\mathrm{F}$ & M \\
\hline Mean & 39.20 & 40.89 & 127.53 & 149.41 & 161.05 & 172.50 & 49.17 & 50.14 & 612.36 & 661.50 \\
\hline Std. deviation & 11.38 & 10.39 & 25.35 & 31.54 & 7.03 & 7.58 & 9.28 & 9.78 & 164.71 & 186.76 \\
\hline Minimum & 15.00 & 19.00 & 64.00 & 82.00 & 140.00 & 154.00 & 24.69 & 28.08 & 250.00 & 300.00 \\
\hline Maximum & 66.00 & 64.00 & 220.00 & 240.00 & 188.00 & 196.00 & 81.80 & 81.49 & 1030.00 & 1300.00 \\
\hline
\end{tabular}



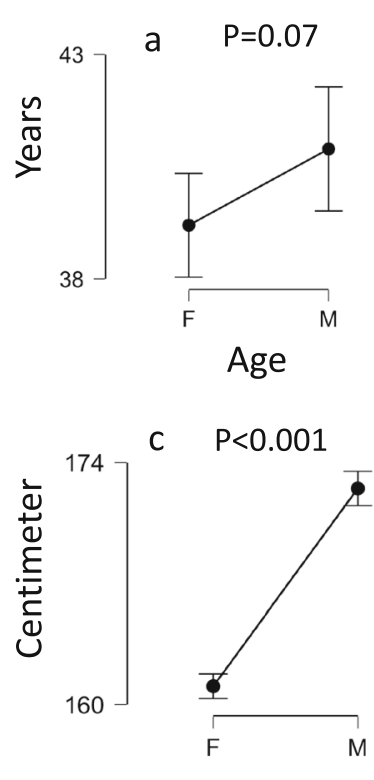

Height

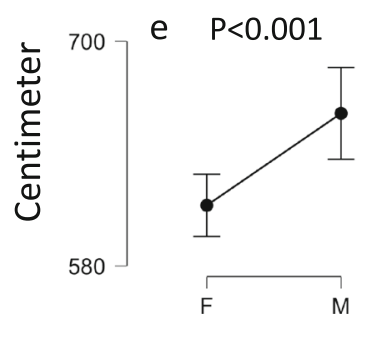

TSBL

Fig. 2 Error bar depicting the differences in the tested variables between genders estimated with Student's $t$ test

It is interesting to note that the degree of stretching of the bowel during the measurement can be an important source of variation. Tacchino reported approximately $130 \mathrm{~cm}$ difference between the stretched and relaxed measures [20]. In turn, in vivo measurements could be different from ex vivo measurements. This could be mainly attributed to the muscle tone of the bowel in living being as opposed to post-mortem.

Our study reported measurement under no stretching of the bowel. Hence, a difference of around $1 \mathrm{~m}$ could be expected if these measures were taken under stretching of the small bowel. Noteworthy, the average length reported herein is longer than other in vivo studies [14].

In this study, we observed that the TSBL is significantly longer in males compared with females. This finding is in agreement with previous reports in the literature [18]. Interestingly, we observed that the correlation between TSBL and height is stronger in males than females but with no statistical difference. Noteworthy, we previously reported on the gender influence on the outcome of bariatric surgery $[7,21]$. Perhaps that the previously observed difference could be at least partially attributed to the difference in the TSBL.

There is no agreement on the relationship trend between the TSBL and the anthropometric measures in the literature [22]. The study beforehand demonstrates that TSBL poorly correlates to the anthropometric parameters. The correlation with height was statistically significant however, in clinical terms, weak. The coefficient of determination (effect size) is sufficiently low to make the clinical prediction unreliable. Similar to this study, Tacchino found a significant relationship between the height of individuals and the TSBL [20]. Other authors reported no correlation between the TSBL and the height but interestingly with the weight [18]. A landmark study was performed post-mortem in infants and showed that TSBL plateaus in after certain height [23]. We observed a negative but weak correlation between age and TSBL.
Fig. 3 Correlation scatter plot of the TSBL and a weight, $\mathbf{b}$ height, c BMI, and $\mathbf{d}$ age for females
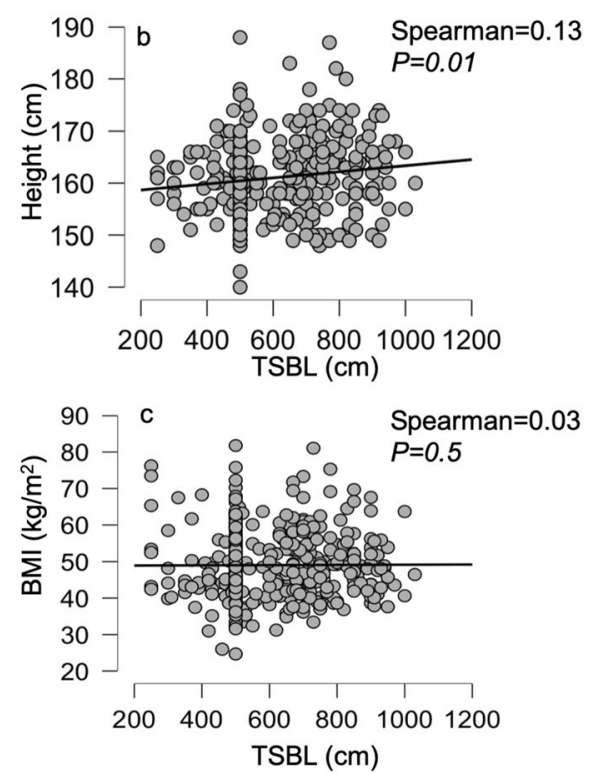
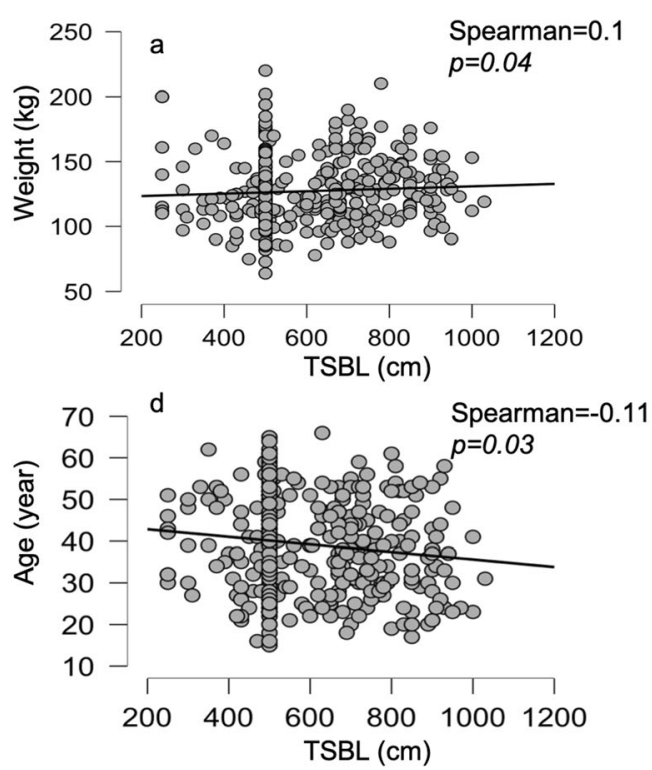
Fig. 4 Correlation scatter plot of the TSBL and a weight, $\mathbf{b}$ height, c BMI, and $\mathbf{d}$ age for males
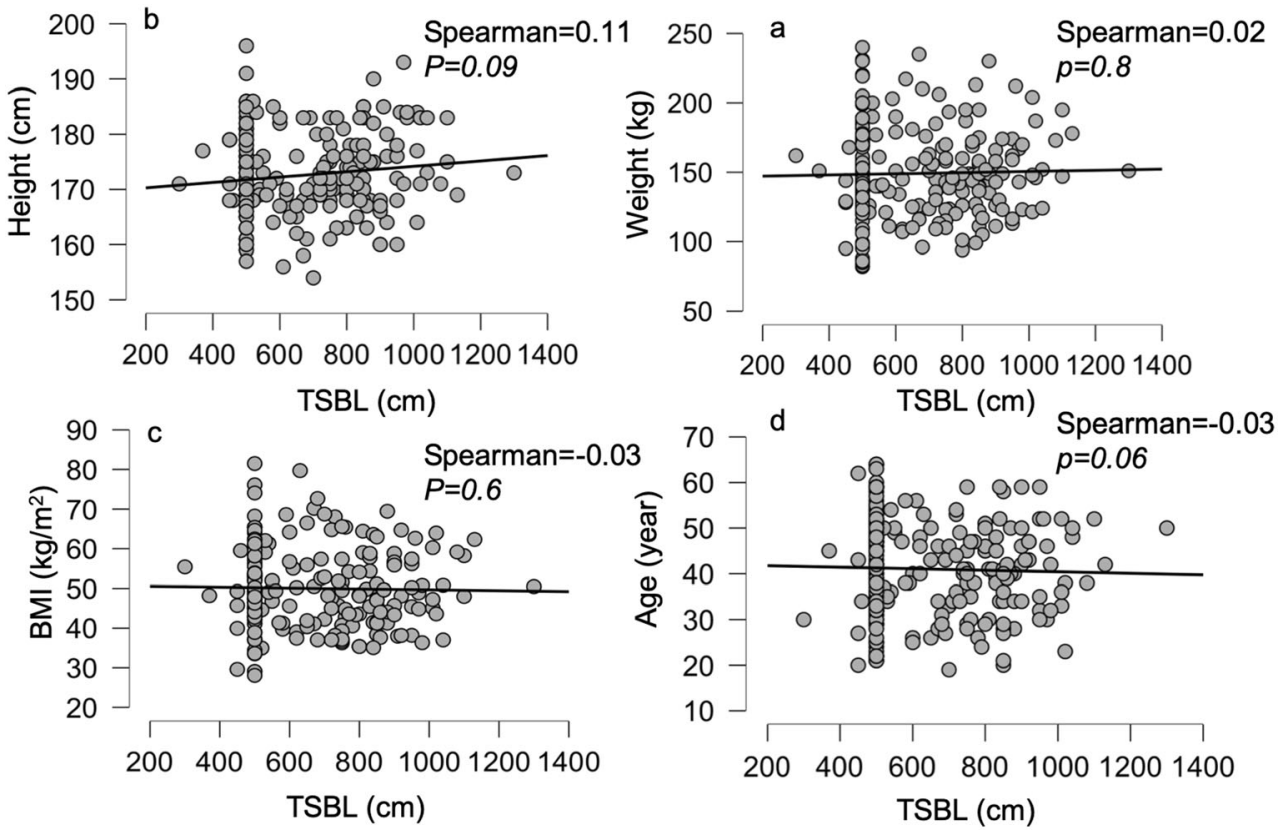

This study reinforces the knowledge on the in vivo measures of the average TSBL. However, it demonstrates that the variability is greater than what is reported in the literature. It could have been interesting to repeat the measures with maximal stretch to estimate its influence on the measurements. Knowledge on the segmental physiology in relation to the total bowel length is not present in the literature and this study did not contribute to this knowledge.

\section{Conclusion}

Despite statistical significance of the correlation between the TSBL and the height and weight of the included participants, the correlation seems to have no clinical meaning since the effect size is negligible. The variation of the TSBL in our series is larger than what has been previously reported.

\section{Compliance with Ethical Standards}

Conflict of Interest The authors declare that they have no conflict of interest.

Ethical Approval All procedures performed in studies involving human participants were in accordance with the ethical standards of the institutional and national research committee and with the 1964 Helsinki declaration and its later amendments or comparable ethical standards.

Open Access This article is distributed under the terms of the Creative Commons Attribution 4.0 International License (http:// creativecommons.org/licenses/by/4.0/), which permits unrestricted use, distribution, and reproduction in any medium, provided you give appropriate credit to the original author(s) and the source, provide a link to the Creative Commons license, and indicate if changes were made.

\section{References}

1. Livingston EH. The incidence of bariatric surgery has plateaued in the U.S. Am J Surg. 2010;200:378-85. https://doi.org/10.1016/j. amjsurg.2009.11.007.

2. Clapham JC. Treating obesity: pharmacology of energy expenditure. Curr Drug Targets. 2004;5:309-23.

3. Abdel-Salam WN, Bekheit M, Katri K, et al. Efficacy of intragastric balloon in obese Egyptian patients and the value of extended liquid diet period in mounting the weight loss. J Laparoendosc Adv Surg Tech A. 2013;23:220-4.

4. Abeles D, Shikora SA. Bariatric surgery: current concepts and future directions. Aesthetic Surg J. 2008;28:79-84. https://doi.org/10. 1016/j.asj.2007.09.007.

5. Bult MJF, van Dalen T, Muller AF. Surgical treatment of obesity. Eur J Endocrinol. 2008;158:135-45. https://doi.org/10.1530/EJE07-0145.

6. Schouten R, Wiryasaputra DC, van Dielen FMH, et al. Long-term results of bariatric restrictive procedures: a prospective study. Obes Surg. 2010;20:1617-26. https://doi.org/10.1007/s11695-010-02112.

7. Bekheit M, Katri K, Ashour MH, et al. Gender influence on longterm weight loss after three bariatric procedures: gastric banding is less effective in males in a retrospective analysis. Surg Endosc Other Interv Tech. 2014;28:2406-11.

8. Quan V, Cooper FPM, Bekheit M. The influence of total bowel length on gastric bypass outcomes. Mini-Invasive Surg 2017:958. https://doi.org/10.20517/2574-1225.2017.17.

9. Mahawar KK, Kumar P, Parmar C, et al. Small Bowel limb lengths and Roux-en-Y gastric bypass: a systematic review. Obes Surg. 2016;26:660-71. https://doi.org/10.1007/s11695-016-2050-2.

10. Svanevik M, Risstad H, Hofsø D, et al. Perioperative outcomes of proximal and distal gastric bypass in patients with BMI ranged 50 $60 \mathrm{~kg} / \mathrm{m}$ (2)-a double-blind, randomized controlled trial. Obes Surg. 2015;25:1788-95. https://doi.org/10.1007/s11695-015-1621-y.

11. UNDERHILL BM. Intestinal length in man. Br Med J. 1955;2: 1243-6. https://doi.org/10.1136/bmj.2.4950.1243.

12. Nightingale JM, Lennard-Jones JE. The short bowel syndrome: what's new and old? Dig Dis. 1993;11:12-31. https://doi.org/10. $1159 / 000171397$. 
13. Touloukian RJ, Smith GJW. Normal intestinal length in preterm infants. J Pediatr Surg. 1983;18:720-3. https://doi.org/10.1016/ S0022-3468(83)80011-6.

14. Teitelbaum EN, Vaziri K, Zettervall S, et al. Intraoperative small bowel length measurements and analysis of demographic predictors of increased length. Clin Anat. 2013;26:827-32. https://doi.org/10. 1002/ca.22238.

15. Marie L, Nacache R, Scemama U, et al. Preoperative prediction of small bowel length using CT scan and tridimensional reconstructions: a new tool in bariatric surgery? Obes Surg. 2018;28:1217-24. https://doi.org/10.1007/s11695-017-3021-y.

16. Nassif PAN, Malafaia O, Ribas CAPM, et al. Estudo da correlação do IMC e comprimento do intestino delgado em pacientes obesos submetidos à cirurgia bariátrica. $\mathrm{ABCD}$ Arq Bras Cir Dig (São Paulo). 2009;22:153-7. https://doi.org/10.1590/S010267202009000300004 .

17. Backman L, Hallberg D. Small-intestinal length. An intraoperative study in obesity. Acta Chir Scand. 1974;140:57-63.

18. Hounnou G, Destrieux C, Desmé J, et al. Anatomical study of the length of the human intestine. Surg Radiol Anat. 2002;24:290-4. https://doi.org/10.1007/s00276-002-0057-y.
19. Treves F. Lectures on the anatomy of the intestinal canal and peritoneum in man. Br Med J. 1885;1:470-4. https://doi.org/10.1136/ bmj.1.1262.470.

20. Tacchino RM. Bowel length: measurement, predictors, and impact on bariatric and metabolic surgery. Surg Obes Relat Dis. 2015;11: 328-34. https://doi.org/10.1016/j.soard.2014.09.016.

21. Bekheit M, Elward AS. Comparing weight loss in three bariatric procedures: Roux-en-Y gastric bypass, vertical banded gastroplasty, and gastric banding; 2016. https://doi.org/10.1016/ B978-0-12-804011-9.00040-6.

22. Raines D, Arbour A, Thompson HW, et al. Variation in small bowel length: factor in achieving total enteroscopy? Dig Endosc. 2015;27: 67-72. https://doi.org/10.1111/den.12309.

23. Reiquam CW, Allen RP, Akers DR. Normal and abnormal small bowel lengths: an analysis Of 389 autopsy cases in infants and children. Am J Dis Child. 1965;109:447-51.

Publisher's Note Springer Nature remains neutral with regard to jurisdictional claims in published maps and institutional affiliations. 